\title{
Effect of Addition of Sodium Citrate in Plasma Extraction for Venous Blood Glucose Determination
}

\author{
Tiago Tizziani' ${ }^{1}$, Diogo Alexandre Siebert ${ }^{1}$, Tassiana Pancotte ${ }^{2}$, \\ Caio Mauricio Mendes de Cordova ${ }^{3}$ \\ ${ }^{1}$ Graduation Program in Chemistry, University of Blumenau, Blumenau, Brazil \\ ${ }^{2}$ Undergraduate Course in Pharmacy, University of Blumenau, Blumenau, Brazil \\ ${ }^{3}$ Department of Pharmaceutical Sciences, University of Blumenau, Blumenau, Brazil \\ Email: cmcordova@furb.br
}

Received 22 February 2014; revised 21 March 2014; accepted 20 April 2014

Copyright (C) 2014 by authors and Scientific Research Publishing Inc.

This work is licensed under the Creative Commons Attribution International License (CC BY).

http://creativecommons.org/licenses/by/4.0/

(c) (i) Open Access

\begin{abstract}
Background: Diabetes Mellitus (DM) is one of the major health problems and morbidity causes in contemporary society worldwide. Recently, it has been suggested that the addition of citrate in plasma extraction decreases glucose degradation by endogenous enzymes, which could contribute in an important manner to the diagnosis of DM. However, this strategy has not been sufficiently evaluated. The present study aimed to evaluate glucose determination in serum and in plasma obtained with different anticoagulants. Methods: We obtained 20 venous blood paired samples on consecutive days from the same individual, collected in dry tubes with separator gel and in glass tubes with sodium fluoride and EDTA- $\mathrm{K}_{2}$, either in the presence or absence of sodium citrate. Glucose was determined by an oxidase/peroxidase method using the same system by a unique analyst. Results: Serum determinations were constantly higher than in plasma $(P<0.02)$, and the addition of citrate increased the analytical variability. Conclusions: Our results were highly relevant statistically, and did not corroborate the addition of citrate in plasma extraction for the inhibition of glycolysis, at least using the standard anticoagulant concentrations.
\end{abstract}

\section{Keywords}

Anticoagulants, Diabetes Mellitus, Glycolysis, Fluoride, Venous Blood

\section{Introduction}

Diabetes Mellitus (DM) diagnosis is established through the identification of hyperglycemia. This strategy is an 
indirect one, since hyperglycemia reflects only the consequence of the metabolic disturbance and not its cause. Until the precise physiopathology of the disease is identified, it is likely that blood glucose determination will remain an essential approach for diagnosis [1].

The stability of glucose in blood samples has been a great challenge in obtaining a confident result that may allow the precise interpretation of glycemic levels, and subsequently the correct management of the diabetic patient. Recently, the addition of citrate in plasma extraction for blood glucose determination has been suggested [1]. Some authors have suggested that citrate would increase glucose stability in the sample by acidifying its $\mathrm{pH}$, therefore inhibiting the action of glycolytic enzymes [2]. However, this new approach has not been properly investigated. Therefore, our aim was to evaluate glucose determination in plasma with different anticoagulants, namely EDTA (Ethylenediaminetetraacetic acid) plus sodium fluoride, in the presence or absence of sodium citrate, in standard concentrations, compared to serum extracted immediately after the collection of peripheral venous blood.

\section{Material and Methods}

Blood samples were analyzed in the clinical laboratory of our institution. A $10 \mathrm{~mL}$ venous sample was collected daily according to standard procedures and split into three different tubes: (S) $4 \mathrm{~mL}$ in a dry tube with separator gel and coagulation accelerator (BD Vacutainer, Becton Dickinson, Plymouth, UK), (F + E) $3 \mathrm{~mL}$ in a glass tube containing sodium fluoride plus $\mathrm{K}_{2}$-EDTA, and $(\mathrm{F}+\mathrm{E}+\mathrm{C}) 3 \mathrm{~mL}$ in a glass tube containing sodium fluoride plus $\mathrm{K}_{2}$-EDTA and sodium citrate. The final concentrations of the salts were $12.9 \mathrm{mM}$ for sodium citrate, 4.55 $\mathrm{mM}$ for $\mathrm{K}_{2}$-EDTA $2 \mathrm{H}_{2} \mathrm{O}$, and $59.54 \mathrm{mM}$ for $\mathrm{NaF}$ [3]. The dry tube was maintained in an ice bath immediately after blood collection for $5 \mathrm{~min}$ and centrifuged at $1500 \mathrm{~g}$ for $10 \mathrm{~min}$ for serum extraction. The other tubes were maintained at room temperature $\left(20^{\circ} \mathrm{C}\right.$ to $\left.24^{\circ} \mathrm{C}\right)$ for $30 \mathrm{~min}$, centrifuged and then the plasma was separated to a clean tube.

Glucose determination was performed by an oxidase/peroxidase method according to the manufacturer's instructions (BioSystems, Barcelona, Spain), always using the same system (BioPlus, Mod. BIO-2000, Barueri, Brazil), and by the same analyst. Data were analyzed by the Student's t Test with one-tailed homoscedastic distribution, by the Bland-Altman plot and by the Deming correlation.

A female volunteer was recruited to supply the blood samples for 20 consecutive days. The participant was a Caucasian, 23-year-old healthy female weighing $58 \mathrm{~kg}$ and had no previous record of blood glucose alterations. During the period of sample collection, the participant abstained from common conditions known to alter blood glucose levels (such as tobacco and alcohol), and fasted for 8 to 10 hrs previous to sampling. The ethical aspect of this study respected the Declaration of Helsinki of 1989 with its further revisions and the International Ethical Guidelines for Biomedical Research Involving Human Subjects (CIOMS/OMS 1982 \& 1993), and was approved by the Ethics Committee on Research with Human Subjects of our institution under the protocol No. 18179813.1.0000.5370.

\section{Results}

Serum glucose determinations were consistently higher than in plasma samples (Figure 1), with a highly significant difference $(\mathrm{P}<0.002)$ (Table 1$)$.

Table 1. Average results (mg/dL), standard deviation (SD), coefficient of variation (CV), Pearson's correlation (r) and statistical significance ( $t$ Test) of glucose levels determined in serum, in plasma with fluoride and EDTA (F + E) and in plasma with fluoride, EDTA and citrate $(F+E+C)$, and the results obtained with the internal control serum (CS) after 20 daily determinations.

\begin{tabular}{cccccc}
\hline$(\mathrm{n}=20)$ & $\mathrm{CS}$ & Serum & $\mathrm{F}+\mathrm{E}$ & $\mathrm{F}+\mathrm{E}+\mathrm{C}$ & $(\mathrm{F}+\mathrm{E}$ versus $\mathrm{F}+\mathrm{E}+\mathrm{C})$ \\
\hline Average & 265.1 & 91.2 & 85.2 & 84.1 & \\
SD & 14.04 & 6.5 & 5.4 & 7.1 & \\
CV & $5.3 \%$ & $7.1 \%$ & $6.4 \%$ & $8.4 \%$ & 0.15 \\
r (Pearson) & & & 0.44 & 0.49 & 0.3041 \\
P (t Test) & & & 0.0004 & 0.0002 & \\
\hline
\end{tabular}


A poor correlation ( $r=0.44$ ) was observed between glucose levels in serum (S) compared to plasma obtained with fluoride and EDTA $(F+E)$, and the addition of citrate did not improve the correlation $(r=0.49)$. The constant error was positive $(22.78 \mathrm{mg} / \mathrm{dL} ; 1.26 \mathrm{mmol} / \mathrm{L})$ for glucose in plasma with $\mathrm{F}+\mathrm{E}$ and negative $(-33.93$ $\mathrm{mg} / \mathrm{dL} ; 1.88 \mathrm{mmol} / \mathrm{L})$ in plasma with fluoride, EDTA and citrate $(\mathrm{F}+\mathrm{E}+\mathrm{C})$. Practically, there was no correlation $(r=0.15)$ between the glucose results obtained with the two plasma types (Figure 2, Table 1).

Glucose levels in plasma with F + E were consistently lower compared to serum (-6.6\%; [-20.1 to 7.2]), and the addition of citrate increased this difference ( $-7.4 \%$; [-23.6 to 8.7]); however, this was not significant ( $\mathrm{P}>$ 0.05) (Figure 3, Table 1).

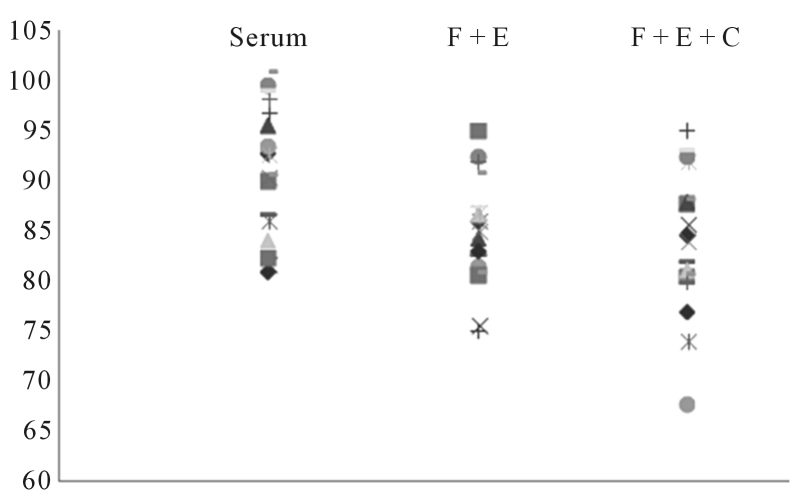

Figure 1. Graphic representation of the dispersion of glucose levels (mg/dL) obtained in serum, in plasma with fluoride and EDTA $(\mathrm{F}+\mathrm{E})$, and in plasma with fluoride, EDTA and citrate $(\mathrm{F}+\mathrm{E}+\mathrm{C})$.
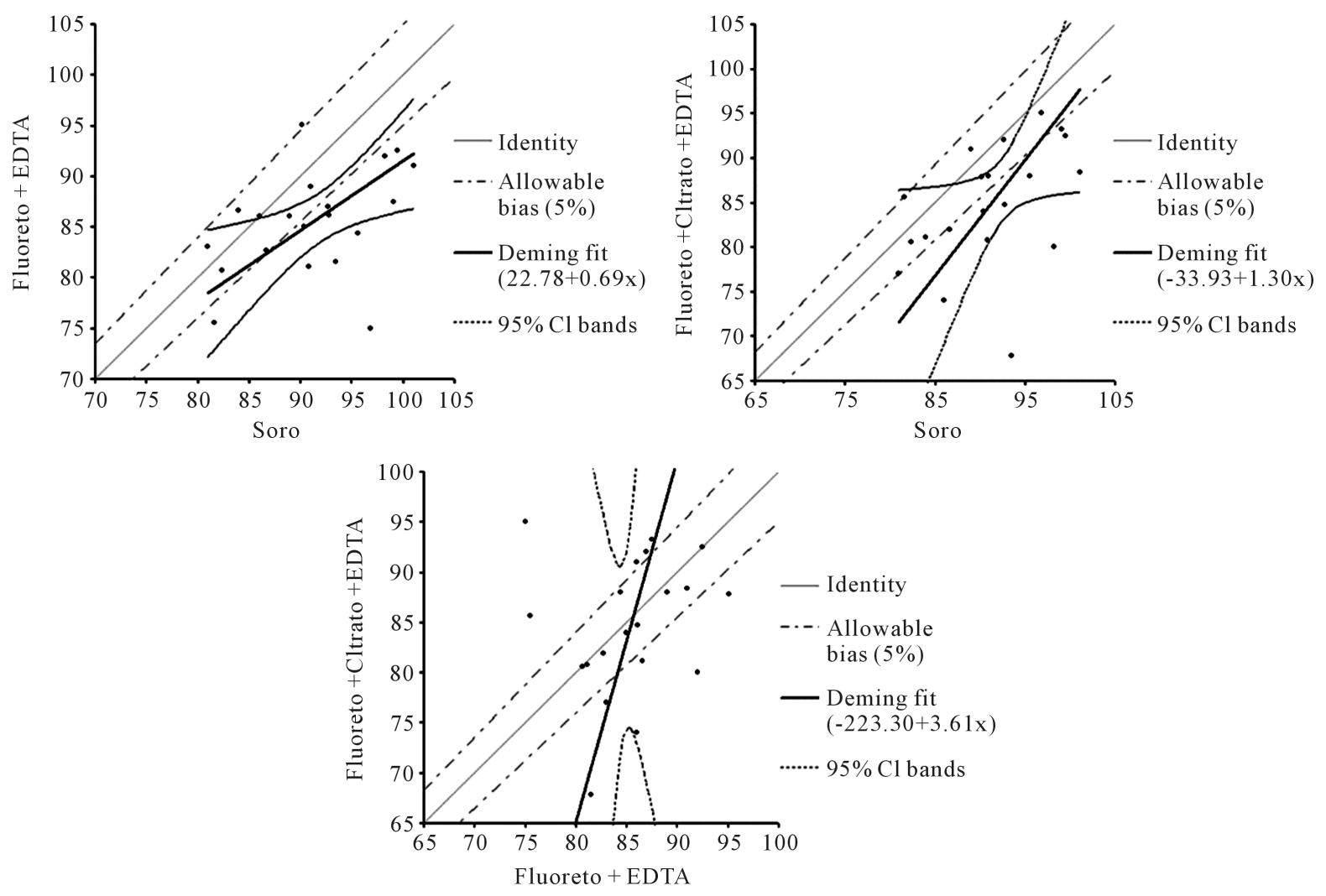

Figure 2. Deming regression demonstrating the correlation of glucose levels $(\mathrm{mg} / \mathrm{mL})$ obtained with the different sample collection and processing methods, considering an allowed bias of 5\% and a confidence interval (CI) of 95\%. 

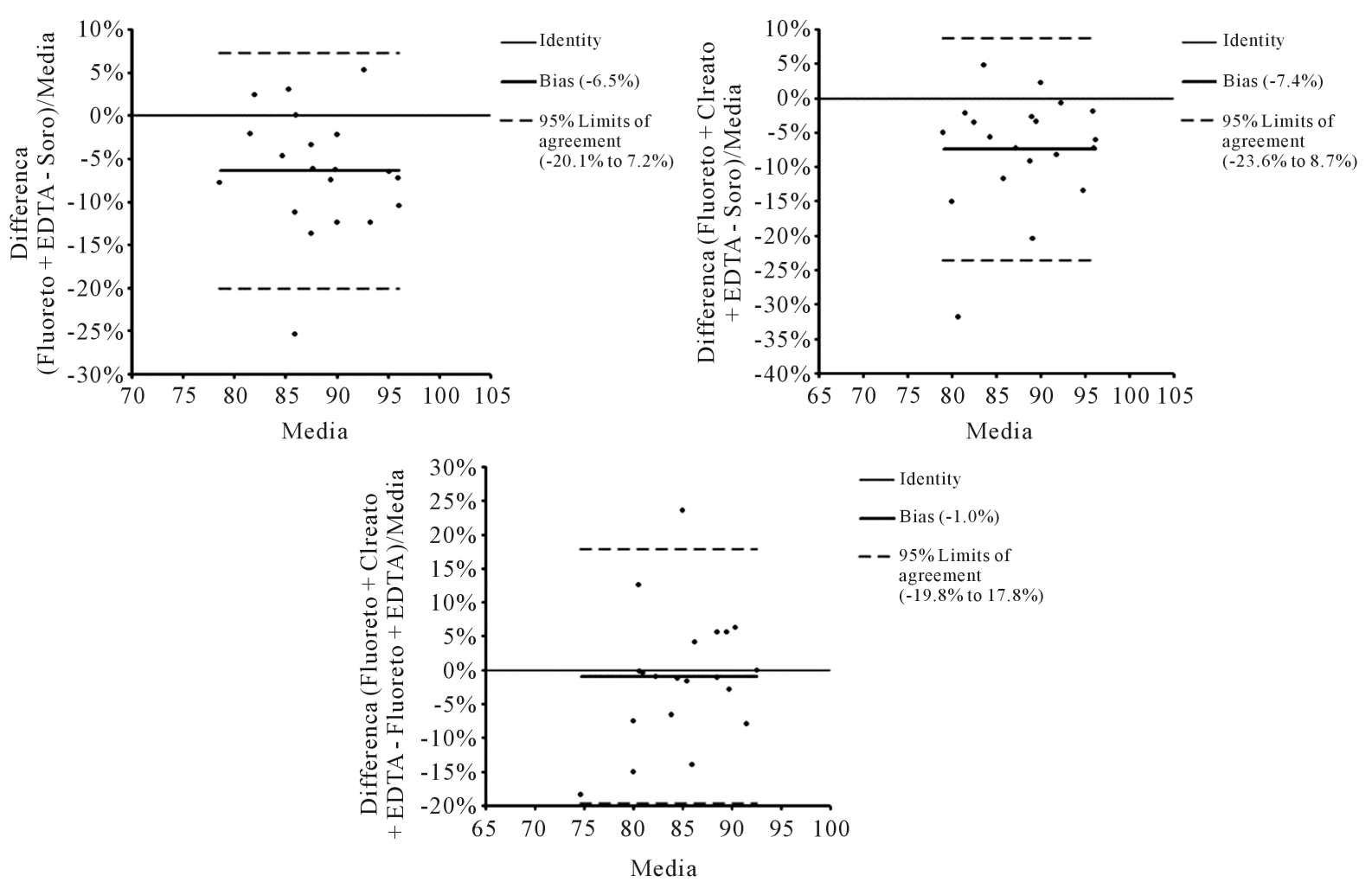

Figure 3. Bland-Altman plot demonstrating the mean difference of glucose levels (mg/dL) obtained with the different methods of plasma extraction compared to serum and the mean difference between the two plasma extraction methods.

\section{Discussion}

Blood glucose determination is extremely important in monitoring the treatment and prevention of DM complications. It is usually performed in plasma samples, with blood collected in tubes with NaF and EDTA or potassium oxalate. If it is not possible to obtain plasma with these anticoagulants, it is recommended that glucose should be determined soon after blood collection or the tube be maintained at $4{ }^{\circ} \mathrm{C}$ for a maximum of $2 \mathrm{hrs}$ [4]. Sodium fluoride inhibits the glycolytic enzyme enolase, decreasing glucose degradation in the sample [5]. A few practical and efficient methods are available for immediate stabilization of glucose in whole blood samples. Glucose degradation can be reduced in two classical ways: 1) immediate separation of serum; and 2) maintaining the whole blood tubes in an ice bath immediately after collection and separate the plasma within 30 min. These methods are not always practical and are not widely used by clinical laboratories [1].

In spite of the recent suggestion of citrate addition to fluorated plasma for blood glucose determination, it was not possible to verify that this new strategy may improve glucose results compared to plasma with fluoride and EDTA only in our study.

Some authors have previously described that the addition of $10 \mathrm{mg}$ per $\mathrm{mL}$ of blood of a mixture of citric acid, trisodium citrate, disodium EDTA, and NaF in a gravimetric proportion of 3.4:1.6:4.8:0.2 would produce and sustain the inhibition of glycolysis for up to 10 hrs at $25^{\circ} \mathrm{C}$ [6]. There is a commercial collection tube containing this mixture, but the concentration of the salts is not provided (Terumo Medical Corporation, NJ, USA). The use of this tube has been demonstrated to be effective in glycolysis inhibition for up to 24 hrs at $37^{\circ} \mathrm{C}$ compared to heparinized plasma maintained for $30 \mathrm{~min}$ at $0^{\circ} \mathrm{C}$, using a hexoquinase method (Olympus America, USA) for glucose determination [2].

Some authors have described that plasma glucose levels would be slightly higher than in serum; however, this subject is relatively controversial, and it is generally considered that this difference is irrelevant, and probably due to the biological variation of blood glucose levels [1]. Therefore, our results, demonstrating that plasma glucose levels are significantly lower than in serum, can only be explained by glycolysis within the time frame of 30 minutes after sample collection. 
It is possible that citrate can interfere with the activity of the enzymes oxidase or peroxidase in the method used for glucose determination in our study, which could, in part, explain the high variability observed between the two types of plasma sample results (with or without the addition of citrate). The glucose oxidase/peroxidase is the most widely used method in our country, mainly because of the cost of the hexoquinase method, but also as a result of the low availability of kits developed for this methodology. The enzyme hexoquinase is not inhibited by citrate. However, this hypothesis does not totally explain the observed variability, since some results were higher in citrated plasma (Figure 1). The concentration of sodium citrate used in our study was that recommended for blood collection for hematological analysis, as no other reference is available [3].

Even if the acidification of plasma does prove to be reliable for glycolysis inhibition, the precise concentration of the citrate to be added is yet to be determined, as is its influence on the variability of the different methods available for glucose determination.

\section{Conclusion}

The results observed in our study are highly relevant statistically, were obtained from paired samples from a single volunteer to exclude inter-individual variability, and were tested by the same analyst, simulating an ideal procedure of sample collection and handling in a clinical laboratory facility. Our findings do not corroborate the addition of standard concentrations of citrate in plasma extraction for blood glucose determination, as this can even increase the analytical variability of the oxidase/peroxidase method.

\section{Acknowledgements}

The authors thank FURB/PROPEX Call No. 05/2013 for supporting this work.

\section{References}

[1] Sacks, B.D., Arnold, M., Brakri, G.L., Bruns, D.E., MacDonald, J.M. and Parrot, M. (2011) Guidelines and Recommendations for Laboratory Analysis in the Diagnosis and Management of Diabetes Mellitus. Clinical Chemistry, 48, 436-472.

[2] Gambin, R., Piscitelli, J., Ackattupathil, T.A., Theriault, J.L., Andrin, R.D., Sanfilippo, M.L. and Etienne, M. (2009) Acidification of Blood Is Superior to Sodium Fluoride Alone as an Inhibitor of Glycolysis. Clinical Chemistry, 55, 1019-1021. http://dx.doi.org/10.1373/clinchem.2008.121707

[3] Clinical and Laboratory Standards Institute (2003) H1-A5. Evacuated Tubes and Additives for Blood Specimen Collection, Approved Standard. 5th Edition, Vol. 23, CLSI, Wayne.

[4] Viggiano, C.E. (2007) A Review about Diabetes Mellitus. (Uma Revisão Sobre Diabetes Melito). Revista Brasileira de Ciências da Saúde, 3, 52-62.

[5] Chan, A.Y., Swaminathan, R. and Cockram, C.S. (1989) Effectiveness of Sodium Fluoride as a Preservative of Glucose in Blood. Clinical Chemistry, 35, 315-317.

[6] Uchida, K., Matuse, R., Toyoda, E., Okuda, S. and Tomita, S. (1988) A New Method of Inhibiting Glycolysis in Blood Samples. Clinica Chimica Acta, 172, 101-108. http://dx.doi.org/10.1016/0009-8981(88)90125-8 